\title{
SURGICAL SITE INFECTION FOLLOWING LOWER SEGMENT CAESAREAN SECTION IN A TERTIARY CARE HOSPITAL
}

\author{
Nishi Roshini Kondakasseril1, Nishitha Hiran², Andrews Mekkattukunnel Andrews ${ }^{3}$ \\ ${ }^{1}$ Additional Professor, Department of Obstetrics and Gynaecology, Govt. Medical College, Manjeri. \\ 2Senior Resident, Department of Obstetrics and Gynaecology, Govt. Medical College, Thrissur. \\ 3Professor, Department of Medicine, Govt. Medical College, Thrissur.
}

\section{ABSTRACT}

\section{AIM OF THE STUDY}

To identify infection rates and risk factors associated with Surgical Site Infection (SSI) following Caesarean Section.

\section{DESIGN OF THE STUDY}

Case control study.

\section{PLACE OF STUDY}

Academic Tertiary Care Obstetrics and Gynaecology Centre with 60 Beds.

\section{PATIENTS} 2011.

All women who delivered by caesarean section in Govt. Medical College, Thrissur, during 1st June 2010 to 30 th September

\section{METHODS}

Wound infections were identified during hospital stay using the criteria of the Centres for Disease Control and Prevention, National Nosocomial Infections Surveillance System. A case control study of 50 patients with wound infection after Lower Segment Caesarean Section (LSCS) was undertaken between 1st June 2010 and 30th September 2011. The control group comprised of 50 patients selected randomly from among those who had LSCS during the study period with no wound infection. The CDC definition describes three levels of SSI (Superficial incisional, Deep incisional and Organ or Space infection). Comparisons for categorical variables were performed using the $\mathrm{X} 2$ or Fisher exact test. Continuous variables were compared using the 2 -tailed Student ' $\mathrm{t}$ ' test and p 0.05 was considered significant.

\section{RESULTS}

The overall wound infection rate in the study was 3.5\%, (50) among 1410 Lower Transverse CS. Obesity, Hypertension and Poorly Controlled Diabetes are associated with significant risk for development of SSI. The commonest presentation of SSI in LSCS was fever $40(80 \%)$ followed by local pain and induration 25 (50\%). SSI was detected on $6 \pm 3$ days. Average duration of hospital stay among SSI was $22.78 \pm 10.2$ days. Staphylococcus aureus was the commonest pathogen for SSI in our series. The increase in the presence of (Methicillin Resistant Staphylococcus Aureus) MRSA (20.83\%) might alter the pattern of prophylactic antibiotic given preoperatively in the near future.

\section{CONCLUSIONS}

Increased incidence of drug resistant organisms needs proper attention and strategies for their containment.

\section{KEYWORDS}

SSI - Surgical Site Infection, LSCS - Lower Segment Caesarean Section, CS - Caesarean Section.

HOW TO CITE THIS ARTICLE: Kondakasseril NR, Hiran N, Andrews AM. Surgical site infection following lower segment caesarean section in a tertiary care hospital. J. Evolution Med. Dent. Sci. 2016;5(24):1306-1309, DOI: 10.14260/jemds/2016/305

\section{INTRODUCTION}

Surgical site infection is defined as infection occurring within 30 days after the operation if no implant is left in place or within 1 year if implant is in place and the infection appears to be related to the operation. Infections of the surgical wound are one of the most common Hospital Acquired

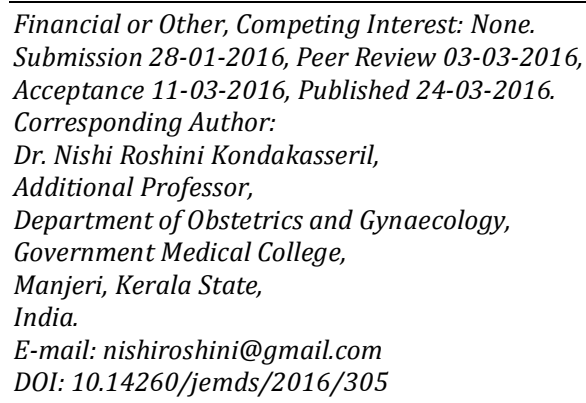

Infection (HAI). Delivery by caesarean section is the most important risk factor for maternal infection. (1)

Wound infections following Caesarean Section (CS) increases maternal morbidity and cost. (2) SSIs can range from a relatively trivial wound discharge with no other complications to life-threatening sepsis. The rate of wound infection after CS ranges from $3-16 \%$ in recent studies.(2) The rate of wound infection reported depend on the surveillance methods used to identify infections, the patient population and the use of prophylactic antibiotics.(2)

In most instances, these are avoidable.(3) Surveillance for SSI is important to prevent them.(4) CS is the most commonly performed surgical procedure in obstetric practice. The risk factors for postoperative CS wound infection and the proportion of SSI have not been well documented in Kerala. The purpose of this study is to identify 
the aetiology of SSI and factors contributing to wound infection following CS performed at a tertiary care hospital of Trichur, Kerala.

\section{PATIENTS AND METHODS}

The study was carried out between 1st June 2010 and 30th September 2011 at GMC Thrissur, Kerala, which is the main referral centre in the region. During the period of study, there were 3427 deliveries and 1410 (41.14\%) Lower Segment Caesarean Sections (LSCS) in the hospital. A case control study to identify the clinically relevant risk factors for wound infection after caesarean was undertaken. The data was collected from 1st June 2010 to 30th September 2011 in a series till 50 cases are recruited for the study.

Criteria used to diagnose wound infection were as defined in the Centres for Disease Control and Prevention's National Nosocomial Infections Surveillance Systems. Wound infection was diagnosed if at least one of the following signs or symptoms of infection are present such as fever $\left(>38^{\circ} \mathrm{c}\right)$ pain or tenderness, localized swelling, redness, heat, abscess, purulent discharge from the wound and/or positive culture of the wound swab. Organ/Space infection was diagnosed if purulent drainage from a drain that is placed through a stab wound or organisms isolated from an aseptically obtained culture of fluid or tissue in organ/space. An abscess or other evidence of infection involving the organ/space that is found on direct examination, during re-operation or by histopathological or radiological examination.

Wound swabs were cultured for both aerobic and anaerobic microorganisms. According to hospital policy, all CS patients remained hospitalized for 6-7 days until primary wound healing had occurred. Demographic data for each of the patients included Age, Parity, Body Mass Index (BMI) on admission, details of previous obstetric history including previous CS, medical complications in pregnancy such as Diabetes Mellitus (DM), hypertension, renal disease, SLE, gestational age at delivery, Prolonged Rupture of Membranes (PROM), operation time and blood loss during CS and use of antibiotics were collected. Categorical variables in the two groups were compared by using X2 or Fisher exact test. Continuous variables were compared using the Student ' $\mathrm{t}$ ' test and $\mathrm{p} \# 0.05$ was considered statistically significant. SPSS version 16.0 was used to perform the statistical analyses. Approval for this study was obtained from the Institutional Research Board.

\section{RESULTS}

A total of 1410 cases of caesarean sections were performed in the study period. Among them 50 (4.2\%) had wound infection. In the cases, 14 (28\%) had elective and 36 (72\%) had emergency caesarean sections. The average age of the LSCS patients was $27.06 \pm 3.72$ years in the study group and $26.72 \pm 3.68$ in the control group. Age and parity were not significant factors for wound infection in the study. The maternal variables associated with wound infection after LSCS are shown in Table 1.

\begin{tabular}{|c|c|c|c|c|}
\hline $\begin{array}{c}\text { Maternal } \\
\text { Risk } \\
\text { Factor }\end{array}$ & $\begin{array}{c}\text { SSI } \\
\text { Group } \\
\mathbf{n = 5 0}\end{array}$ & $\begin{array}{c}\text { Controls } \\
\mathbf{n = 5 0}\end{array}$ & $\begin{array}{c}\text { OR } \\
\mathbf{( 9 5 \%} \mathbf{~ C I})\end{array}$ & $\begin{array}{c}\mathbf{p} \\
\text { Value }\end{array}$ \\
\hline Age & $27.06 \pm 3.72$ & $26.72 \pm 3.68$ & -1.1285 to 1.8085 & 0.6469 \\
\hline $\begin{array}{c}\text { Haemo- } \\
\text { globin } \\
\text { (gm\%) }\end{array}$ & $11.12 \pm 1.69$ & $11.24 \pm 1.65$ & -0.7829 to 0.5429 & 0.7202 \\
\hline
\end{tabular}

\begin{tabular}{|c|c|c|c|c|}
\hline $\begin{array}{c}\text { Body mass } \\
\text { index } \\
(\mathrm{kg} / \mathrm{m} 2)\end{array}$ & $27.36 \pm 2.02$ & $23.72 \pm 2.09$ & 2.8243 to 4.4557 & 0.0001 \\
\hline $\begin{array}{c}\text { Fasting } \\
\text { Sugar } \\
\text { (mg\%) }\end{array}$ & $91 \pm 17$ & $82 \pm 11$ & 3.32 to 14.68 & 0.0022 \\
\hline $\begin{array}{c}\text { Hyper- } \\
\text { tension }\end{array}$ & $12(24 \%)$ & $2(4 \%)$ & $1.59-35.93$ & 0.010 \\
\hline $\begin{array}{c}\text { Duration } \\
\text { of surgery } \\
\text { in minutes }\end{array}$ & $49 \pm 13$ & $57 \pm 12$ & -12.97 to -3.03 & 0.0019 \\
\hline \multicolumn{5}{|c|}{ Table 1: Maternal Risk Factors of SSI among } \\
LSCS for Cases and Controls
\end{tabular}

SSI - Surgical Site Infection, LSCS - Lower Segment Caesarean Section.

Excessive blood loss requiring transfusion was present in 2 patients with SSI who developed peritonitis. They were empirically started on Piperacillin-Tazobactam and Amikacin and improved.

SSI was detected on $6 \pm 3$ days. The commonest clinical manifestation of SSI in our study was fever in $40(80 \%)$ cases. Local pain and induration was seen in 25 (50\%) cases and purulent discharge in 20 (40\%) cases; 15 (30\%) women had spontaneous superficial dehiscence wound and in $12(24 \%)$ women wound was deliberately opened to facilitate drainage of pus. Resuturing was done in these 27 cases. No intraperitoneal drain was put in study group or among controls.

\begin{tabular}{|c|c|c|}
\hline Clinical Presentation & Frequency & Percent \\
\hline Fever & 40 & $80 \%$ \\
\hline Local pain and induration & 25 & $50 \%$ \\
\hline Purulent discharge wound & 20 & $40 \%$ \\
\hline $\begin{array}{c}\text { Spontaneous superficial } \\
\text { dehiscence wound }\end{array}$ & 15 & $30 \%$ \\
\hline Wound deliberately opened & 12 & $24 \%$ \\
\hline Pelvic collection in USG & 2 & $4 \%$ \\
\hline Resuturing & 27 & 54 \\
\hline \multicolumn{3}{|c|}{ Table 2: Clinical Presentation of SSI in LSCS } \\
\hline
\end{tabular}

SSI - Surgical Site Infection, LSCS - Lower Segment Caesarian Section.

Superficial infection was seen in $36(72 \%)$ and deep infection in 12 (24\%) and Organ/Space SSI in 2 (4\%).

\begin{tabular}{|c|c|c|}
\hline Type & Number & Percent \\
\hline Superficial incisional & 36 & 72 \\
\hline Deep incisional & 12 & 24 \\
\hline Organ/space & 02 & 4 \\
\hline \multicolumn{2}{|c|}{ Table 3: Types of SSI following LSCS } \\
\hline
\end{tabular}

SSI - Surgical Site Infection, LSCS - Lower Segment Caesarean Section.

48 patients with wound infection had wound swab cultures done and 6 (12\%) yielded no growth. In 28 (56\%) cases Staphylococcus aureus in 10 (20\%), MRSA in 4 (8\%), E. coli were grown.

\begin{tabular}{|c|c|c|}
\hline Type of Organism & Frequency & Percent \\
\hline E. coli & 4 & 8.33 \\
\hline MRSA & 10 & 20.83 \\
\hline Staphylococcus aureus & 28 & 58.33 \\
\hline Sterile & 6 & 12 \\
\hline Total & 48 & 100.0 \\
\hline
\end{tabular}


SSI - Surgical Site Infection, LSCS - Lower Segment Caesarean Section.

Empirically used antibiotics are shown in Table 5. Most commonly used antibiotic was Ampicillin in our study, 26 (52\%). Antibiotic was changed depending upon the culture and sensitivity in 18 cases of SSI group.

\begin{tabular}{|c|c|c|}
\hline Antibiotic & Frequency & Percent-age \\
\hline Ampicillin & 26 & 52 \\
\hline Ampicillin plus Metronidazole & 14 & 28 \\
\hline $\begin{array}{c}\text { Ampicillin, Metronidazole and } \\
\text { Amikacin }\end{array}$ & 1 & 2 \\
\hline $\begin{array}{c}\text { Benzyl penicillin, Amikacin } \\
\text { and Cloxacillin }\end{array}$ & 2 & 4 \\
\hline Benzyl penicillin, Gentamycin & 2 & 4 \\
\hline $\begin{array}{c}\text { Cefotaxime and } \\
\text { metronidazole }\end{array}$ & 3 & 6 \\
\hline $\begin{array}{c}\text { Piperacillin/Tazobactam plus } \\
\text { Amikacin }\end{array}$ & 2 & 4 \\
\hline \multicolumn{2}{|c|}{ Table 5: Antibiotics use in SSI following LSCS } \\
\hline
\end{tabular}

SSI - Surgical Site Infection, LSCS - Lower Segment Caesarean Section.

Average duration of hospital stay among SSI was $22.78 \pm 10.2$ days and $6.72 \pm 1.48$ in control group. Prophylactic antibiotic was not given preoperatively among 14 cases among LSCS, which were elective caesarean sections and similar number of patients in control group also did not receive any antibiotic. No statistically significant association was seen between cases and controls for haemoglobin levels, post prandial sugar, duration of surgery and blood loss.

\section{DISCUSSION}

SSI is the most common nosocomial infection following surgery.(5) The rates of SSI after caesarean section reported in the literature range from $3 \%$ to $15 \%$ and our incidence of $3.54 \%$ is quite comforting. In a multicentre collaborative study of SSI following CS in the UK reported overall wound problem of $13.6 \%$ and SSI of $8.9 \%$.(6) $^{(6)}$ They prospectively studied CS wound infection including the use of postdischarge surveillance. SSI may not be detected for several weeks after discharge and may not attend the operating hospital.(1) We did not use post-discharge surveillance in our series and so the actual number may be high short postoperative stays following caesarean section delivery make it difficult to assess Surgical Site Infection (SSI) properly.(7) Nearly all our patients had antibiotic prophylaxis in labour and may also contribute to low incidence of SSI.

The additional hospital stay in our study was 16.06 days. This will result in prolonged period of hospitalization with direct cost and health implications.(8) SSI was detected on $6 \pm 3$ days in this study. The majority of inpatient SSIs developed between day 2 and day 7 in a study from Scotland.(9)

Anaemia was taken as a surrogate marker for malnutrition in this study as the assessment of macro as well as micronutrients is cumbersome, time consuming and costly. In our study, no significant differences were observed between the groups for anaemia. No significant differences were seen between study groups for WBC counts or platelet counts.

In the present study Body Mass Index (BMI) was $27.36 \pm 2.02$ in women with infection, while it was $23.72 \pm 2.09$ in the control group. The risk of developing an inpatient SSI is higher in patients with a BMI category of overweight or obese.(9)

Regarding the glycaemic controls different studies had done glucose estimations differently. It is generally agreed upon that euglycaemia is beneficial in preventing SSI.(10) But no consensus is reaching upon regarding the timing of blood sugar estimation and how strict the control should be.(11) In the study by Ata A. et al. postoperative hyperglycaemia was significant risk factor. There was some difference between the groups in fasting sugar levels. High fasting sugar levels were associated with significant risk of developing SSI $(p<0.05)$ in our study. Hypertension, diabetes and anaemia were the common comorbid conditions identified in the study population. A cut-off of haemoglobin $<10 \mathrm{gm} / \mathrm{dL}$ was taken to define anaemia. But as shown before the glycaemic control is more important as high fasting blood sugar levels were associated with significant risk of developing an SSI.

Mangram et al. has noted association for duration of surgery with risk of SSI where the surgery lasted for $>3$ hours.(12)

Staphylococcus aureus was the commonest pathogen to produce SSI in our series and goes in accordance with the literature reviews. More than $50 \%$ of SSI is caused by Staphylococcus aureus, because it is highly virulent. Staphylococcus epidermidis is less virulent and usually causes SSI only in patients who are already immunocompromised.(13) The increase in the presence of MRSA (20.83\%) in study group is a serious concern. This may alter the pattern of prophylactic antibiotic given preoperatively in the near future if their incidence is on the rise.

As per ACOG guidelines cefazolin is recommended routinely for LSCS as a prophylactic measure.(14) The use of either cefazolin alone prior to surgical incision or an extended-spectrum regimen after cord clamp appears to be associated with a reduction in post caesarean maternal infection.(14) The commonest antibiotic used in the present study was ampicillin in LSCS group. The choice of antibiotic for caesarean section should be a single dose of a firstgeneration cephalosporin. If the patient has penicillin allergy, clindamycin or erythromycin can be used. The timing of prophylactic antibiotics for caesarean section should be 15 to 60 minutes prior to skin incision. No additional doses are recommended. If an open abdominal procedure is lengthy $(>3$ hours) or estimated blood loss is greater than $1500 \mathrm{~mL}$, an additional dose of the prophylactic antibiotic may be given 3 to 4 hours after the initial dose.(15)

\section{CONCLUSION}

The distribution and pathogens of Surgical Site Infections (SSIs) has not changed much over the years. Staphylococcus aureus and Escherichia coli remain the most frequently isolated pathogens. An increasing proportion of SSIs are caused by antimicrobial-resistant pathogens, such as Methicillin-Resistant S. Aureus (MRSA). Steps to be taken to implement prophylactic antibiotic use as per guidelines.

\section{REFERENCES}

1. Mitt P, Lang K, Peri A, et al. Surgical-site infections following cesarean section in an estonian university hospital: postdischarge surveillance and analysis of risk factors. Infect Control Hosp Epidemiol 2002;26(5):44954. 
2. Al Jama FE. Risk factors for wound infection after lower segment cesarean section. Qatar Med J 2012;2012(2):26-31.

3. Gur R, Duggal SD, Rongpharpi SR, et al. Post caesarean surgical site infections. Archives of clinical microbiology 2015;6(1):1-6.

4. Golia S, Asha S Kamath B, Nirmala AR. A study of superficial surgical site infections in a tertiary care hospital at Bangalore. Int J Res Med Sci 2014;2(2):647652.

5. John H, Nimeri A, Ellahham S. Improved surgical site infection (SSI) rate through accurately assessed surgical wounds. BMJ Qual Improv Reports 2015;4(1). doi:10.1136/bmjquality.u205509.w2980.

6. Jido T, Garba I. Surgical-site infection following cesarean section in Kano, Nigeria. Ann Med Health Sci Res 2012;2(1):33-6.

7. Wilson J, Wloch $\mathrm{C}$, Saei $\mathrm{A}$, et al. Inter-hospital comparison of rates of surgical site infection following caesarean section delivery: evaluation of a multicentre surveillance study. J Hosp Infect 2013;84(1):44-51.

8. Donowitz LG, Wenzel RP. Endometritis following cesarean section a controlled study of the increased duration of hospital stay and direct cost of hospitalization. Am J Obstet Gynecol 1980;137(4):4679.
9. Pan Celtic report-Surveillance of surgical site infection for caesarean section procedures performed in 2008 . Cited Dec 27 2015. Available from: http://www.documents.hps.scot.nhs.uk/hai/sshaip/pu blications/pan-celtic-report/pan-celtic-report-ssicaesarean-2008.

10. Sehgal R, Berg A, Figueroa R, et al. Risk factors for surgical site infections after colorectal resection in diabetic patients. J Am Coll Surg 2011;212(1):29-34.

11. Talbot TR. Diabetes mellitus and cardiothoracic surgical site infections. Am J Infect Control 2005;33(6):353-9.

12. Mangram AJ, Horan TC, Pearson ML, et al. Guideline for prevention of surgical site infection. Am J Infect Control 1999;27(2):97-132.

13. Gould D. Causes, prevention and management of surgical site infection. Nurs Stand 2012;26(47):47-57.

14. Tita ATN, Rouse DJ, Blackwell S, et al. Emerging concepts in antibiotic prophylaxis for cesarean delivery: a systematic review. Obstet Gynecol 2009;113(3):67582.

15. Van Schalkwyk J, Van Eyk N. Antibiotic prophylaxis in obstetric procedures. J Obstet Gynaecol Canada 2010;32(9):878-92. 